\title{
GESTÃO DE PROCESSOS NA ADMINISTRAÇÃO PÚBLICA: o caso da Diretoria de Cálculos e Perícias do município de Belo Horizonte
}

\author{
PROCESS MANAGEMENT IN PUBLIC ADMINISTRATION: \\ the case of the Directorate of Calculations and Expertise of the county of Belo Horizonte
}

\section{Resumo}

Lyllian Nietzsch Lima Melo

Especialista em Gestão Pública Universidade Federal de Minas Gerais - UFMG

Belo Horizonte, Minas Gerais - Brasil lyllianlima@yahoo.com.br

Daniel Francisco Bastos Monteiro Mestre em Administração Universidade Federal de Minas Gerais - UFMG Santa Bárbara, Minas Gerais - Brasil danielfbmadm@gmail.com

Este estudo tem como objetivo analisar como o processo de trabalho dos calculistas é desenvolvido na Diretoria de Cálculos e Perícias da Procuradoria Geral do Município de Belo Horizonte. Optou-se por desenvolver um trabalho de abordagem qualitativa, utilizando o estudo de caso como estratégia de pesquisa. A coleta de dados foi realizada por meio de entrevistas semiestruturadas e observação não participante direta. Foram entrevistados cinco calculistas, integrantes do quadro funcional da Diretoria de Cálculos, e selecionou-se uma amostra não probabilística intencional. Os dados coletados foram analisados e interpretados a partir da técnica de Análise de Conteúdo. Como principais resultados, constatou-se que, para ter distribuição equânime dos pedidos de conferência entre os calculistas, as ações judiciais teriam que ser mapeadas e agrupadas em níveis, de baixa, média e alta complexidade. Também foi identificada a necessidade de criação de uma equipe de suporte aos procuradores para realizar uma análise minuciosa das ações judiciais visando indicar as atividades a serem executadas e estabelecer prazos a serem cumpridos. E, por fim, evidenciou-se a necessidade de aprimorar a comunicação e integrar as partes envolvidas na execução das ações judiciais. A pesquisa concluiu que o mapeamento e a padronização dos processos devem ser realizados levando em consideração o conhecimento de cada servidor e buscando representar um conjunto de soluções adequadas à otimização de recursos e redução de prazos, proporcionando, assim, produtos e resultados com qualidade e eficiência.

Palavras-chave: Gestão Pública. Gestão de Processos. Administração Pública.

\begin{abstract}
This study aims to analyze how the work process of calculators is developed in the Directorate of Calculations and Expertise of the Attorney General of the Municipality of Belo Horizonte. We chose to develop a qualitative approach, using the case study as a research strategy. Data collection was carried out through semi-structured interviews and direct non-participant observation. Five calculators were interviewed, members of the staff of the Directorate of Calculations and an intentional nonprobabilistic sample was selected. The collected data were analyzed and interpreted using the Content Analysis technique. As main results it was found that to have an equitable distribution of conference requests among the calculators, the lawsuits would have to be mapped and grouped in levels of low, medium and high complexity. It was also identified the need to create a support team for the attorneys to conduct a thorough analysis of the lawsuits in order to indicate the activities to be performed and
\end{abstract}


establish deadlines to be met. And, finally, the need to improve communication and to integrate the parties involved in the execution of lawsuits became evident. The research concluded that the mapping and standardization of the processes must be carried out taking into account the knowledge of each server and seeking to represent a set of appropriate solutions to optimize resources and reduce deadlines, thus providing products with quality and efficiency.

Keywords: Public Management. Mapping Processes. Public Administration.

\section{Cite como - American Psychological Association (APA)}

Melo, L. N. L., \& Monteiro, D. F. B. (2020, set./dez.). Gestão de processos na administração pública: o caso da Diretoria de Cálculos e Perícias do município de Belo Horizonte. Revista de Gestão e Projetos (GeP), 11(3), 136-154.

https://doi.org/10.5585/gep.v11i3.18469.

\section{Introdução}

As mudanças ocorridas nas últimas décadas do século passado e os avanços tecnológicos repercutiram nas organizações que tiveram que rever seus processos de gestão e de trabalho para obter resultados mais significativos. De Sordi (2005) e Kelmi et al. (2015) entendem que as diversas práticas de gestão surgiram com o objetivo de melhorar a competitividade das organizações. A busca por soluções eficazes levou as organizações a reverem suas estruturas, arquitetando-as sob a perspectiva do cliente.

Para Gonçalves (2000), as organizações são uma coleção de processos, e todo trabalho importante, realizado em uma organização, faz parte de algum processo. Ademais, o processo é uma atividade ou conjunto de atividades que toma uma entrada (input), adiciona valor a ele e fornece uma saída (output) a um cliente específico. Nesse sentido, entender como os processos funcionam é importante para determinar como eles devem ser gerenciados para a obtenção do resultado esperado.

Um dos primeiros modelos que focavam em maturidade de processos e compliance foi o Modelo de Maturidade de Processos. O P3M3 (Portfólio, Programa e Modelo de Maturidade de Gestão de Projetos) é parte dos modelos de maturidade do setor P3M (Portfólio, Programa e Gestão de Projetos). O P3M3 visualiza todo o sistema e os processos (Axelos, 2016).

O P3M3 é composto de cinco níveis de maturidade de processos: Nível 1: Conscientização do processo; Nível 2: Repetição do processo; Nível 3: Processo definido; Nível 4: Processo gerenciado; Nível 5: Processo otimizado. Em específico, no nível 2, a organização é capaz de identificar que práticas de gestão foram implementadas e quais processos estão a se desenvolver de modo que possam ser replicados e continuados no futuro. Este nível é caracterizado por uma organização que já apresenta uma determinada abordagem, 
mas, esta ainda não foi plenamente adotada porque há fatores limitantes. A estratégia de comunicação ainda pende melhoria ou pode existir uma experiência limitada no quesito gestão de mudanças (Axelos, 2016).

No Brasil, a União implantou, em 2005, o Programa Nacional de Gestão Pública e Desburocratização (Gespública), o qual foi concebido para ser uma política pública embasada em um modelo de gestão único, na sua essência, público, voltado para o cidadão e buscando seguir os princípios constitucionais da impessoalidade, da legalidade, da moralidade, da publicidade e da eficiência. Dessa forma, tal iniciativa pode evitar desperdícios e tornar a administração mais transparente, assim como definir e identificar competências e responsabilidades conforme pontuam Warrington (1997) e Cruz et al. (2012).

Entendendo que esse novo cenário deve ser adotado em todos os órgãos públicos, este artigo visa abordar os processos que são executados na Diretoria de Cálculos e Perícias (DICP) da Procuradoria Geral do Município (PGM) da Prefeitura de Belo Horizonte, tendo como objetivo geral analisar como o processo de trabalho é desenvolvido neste órgão público. Os objetivos específicos são mapear e analisar as principais dificuldades encontradas no processo e identificar oportunidades de melhoria.

A criação da DICP está relacionada à necessidade de um setor especializado em análise e conferência de cálculos, que garantisse o correto cumprimento das decisões das ações judiciais que tramitavam na Procuradoria. Suas atribuições são o planejamento, a coordenação e a execução de atividades referentes à elaboração e conferência de cálculos e perícias contábeis das ações judiciais das quais o município de Belo Horizonte é parte. Em suma, é responsável pela elaboração de cálculo de todos os processos judiciais, desde a fase inicial até a execução da sentença, inclusive de precatórios judiciais e assistência técnica nas perícias judiciais.

De modo geral, a Diretoria realiza perícia contábil, que é regulada principalmente pelo Novo Código de Processo Civil, Lei 13.105, de 16 de março de 2015. A Perícia Contábil é definida como um conjunto de procedimentos técnicos e científicos destinado a levar à instância decisória elementos de prova necessários a subsidiar a justa solução do litígio, mediante laudo pericial contábil e/ou parecer pericial contábil, em conformidade com as normas jurídicas e profissionais, e a legislação específica no que for pertinente (Sá, 2011).

A informatização dos sistemas nos tribunais judiciais, como o Tribunal de Justiça, o Tribunal Regional do Trabalho, a Justiça Federal e os Juizados Especiais, repercutiu na sistemática de trabalho da Diretoria, pois esta passou a analisar ações judiciais, por meios físico e eletrônico. Desde a implantação do processo eletrônico (PJE), em 2015, houve um crescimento da demanda de trabalho. Outra questão que se apresenta é a maneira como o trabalho é realizado. As solicitações de análise 
e conferência são classificadas num escaninhoprateleira, por prazo de entrega, assunto e valor, sendo que cada calculista seleciona seu trabalho, de acordo com sua área de atuação e nível de complexidade da mesma.

Todavia, do ponto de vista da gestão de operações, sobretudo com foco em processos, sempre há espaço para a melhoria contínua, segundo Pradella (2013). Desse modo, a tentativa de aplicação de modelo teórico para incremento da eficiência e eficácia do trabalho realizado, no sentido de otimizar o tempo e dar celeridade para emissão do parecer técnico é um desafio. Isso porque uma ação judicial simples e/ou menos complexa poderia ser concluída rapidamente, enquanto, nas mais complexas, poderia ser necessário um prazo maior.

O setor pericial é essencial à celeridade e ao equilíbrio orçamentário, portanto, estabelece-se a seguinte questão para nortear a pesquisa: Como o processo de trabalho na DICP pode ser estruturado a fim de obter melhorias em seu conjunto de atividades? Para responder esta questão, será necessário abordar qual metodologia/critério deverá ser utilizada(o) para distribuição dos pedidos de análise e de conferência de cálculos das ações judiciais, desde sua entrada na Diretoria até o processo final, que é a entrega do parecer técnico. Para tanto, este estudo adotou como objetivo de pesquisa analisar como o processo de trabalho dos calculistas é desenvolvido na Diretoria de Cálculos e Perícias da Procuradoria Geral do Município de Belo Horizonte.
No que tange à relevância desta pesquisa, vale destacar que ela vai além da sua aplicabilidade quanto ao mapeamento e à padronização dos processos, pois consiste também em uma oportunidade de dar voz aos integrantes da equipe para apresentar sua percepção do trabalho e indicar melhorias, ao mesmo tempo que proporciona ao gestor uma visão do conjunto de soluções mais adequadas para potencializar os recursos, reduzir prazos e entregar produtos com qualidade e eficiência.

O procedimento empírico utilizado para o desenvolvimento deste trabalho consistiu em uma abordagem qualitativa, utilizando o estudo de caso como estratégia de pesquisa. A coleta de dados foi realizada por meio de entrevistas individuais semiestruturadas e observação não participante direta. Ademais, as entrevistas foram realizadas com cinco calculistas, integrantes do quadro funcional da DICP, e selecionou-se uma amostra não probabilística intencional. No tocante à análise dos dados, os mesmos foram coletados, organizados, analisados e interpretados a partir da técnica de análise de conteúdo.

Além desta introdução, este artigo está organizado nas seguintes seções: a primeira consiste na introdução, em que se contextualizou o problema de pesquisa e apresentou-se o objetivo geral; a segunda refere-se ao referencial teórico, na qual foram abordados o conceito de processo e a gestão de processos no setor público; a terceira é a metodologia, em que foram apresentados os caminhos metodológicos percorridos; a quarta 
consiste na análise e discussão dos resultados; e, por fim, têm-se as considerações finais.

\section{Referencial teórico}

Esta seção está dividida em duas partes principais: algumas definições de processo e o papel da gestão de processos no setor público. $\mathrm{Na}$ primeira parte, apresenta-se a visão de alguns autores em torno do conceito de processo. Já na segunda parte, é delineada uma breve abordagem acerca da gestão de processos no setor público e são apresentadas algumas iniciativas públicas em torno dessa temática.

\subsection{Conceito de processo}

Segundo a Association of Business Process Management Professionals (ABPMP, 2013, p. 35), processo significa "uma agregação de atividade e comportamentos executados por humanos ou máquinas para alcançar um ou mais resultados", resultados estes que visem ao aprimoramento das atividades exercidas, à otimização do tempo realizado e ao cumprimento de prazos estabelecidos pelas instituições, sejam elas públicas e/ou privadas.

O Guia de Gestão de Processos do Gespública, conforme Manual do Brasil (2014), define processo como um conjunto de decisões que transformavam insumos em valores gerados ao cliente/cidadão. Este conceito evoluiu para um "conjunto integrado e sincrônico de insumos, infraestruturas, regras e transformações, que adiciona valor às pessoas que fazem uso dos produtos e/ou serviços gerados". Essa visão reforça a ideia de que processos possuem o compromisso de satisfazer as necessidades dos clientes/cidadãos, exigem sincronia, transformam elementos, seguem orientações e consomem recursos.

Mendonça (2014) pontua que processos podem ser definidos como quaisquer contextos de atividades capazes de receber entradas, realizar algum tipo de transformação e gerar saída, que tendem a ser devolvidas ao ambiente, na forma de bens ou serviços. Em alguns casos, servem como novos elementos de entrada para outras atividades subsequentes. No entanto, é importante ressaltar que os processos existem para agregar valores aos clientes ou às partes interessadas, e, segundo Gonçalves (2000), entender como funcionam e quais são os tipos existentes é necessário para determinar como eles devem ser gerenciados para a obtenção de um resultado esperado.

Adair e Murray (1996) delinearam uma hierarquia para os processos de acordo com sua dimensão e complexidade para conseguir os resultados pretendidos. Assim, sendo os processos definidos pelos autores como: macroprocesso, processo, subprocesso, atividades e tarefa (Longeray et al., 2017). Portanto, processo não é somente o resultado das atividades e tarefas, executadas de forma integrada para produzir um bem ou serviço com vistas a atender as necessidades de clientes, mas também um conjunto de meios articulados que servem para avaliar e revisar os processos da organização, visando melhorá-los para atingir os objetivos no tempo determinado. 
A gestão de processos, para Huntress (2006), visa ao aprimoramento contínuo por meio do conhecimento e documentação de cada atividade no trabalho, e serve para documentar, desenvolver, implementar, monitorar e otimizar, integrando sistemas e pessoas. Já na visão de Paim, Caulliraux e Cardoso (2008), trata-se de um conjunto articulado de tarefas permanentes para projetar e promover o funcionamento e aprendizado sobre os processos. E, segundo Davenport (1994), gestão de processos pode ser entendida como uma forma pela qual as instituições procuram alcançar seus objetivos para serem eficazes com um mínimo de insumos, maximizando seus produtos.

Além de visar à integração de processos, pessoas e tecnologias que resultam na qualidade dos serviços produzidos, Dixon (2012) considera que outros benefícios da gestão de processos são a redução de custos, o aumento de produtividade (eficiência) e a agilidade (rapidez de mudanças). E Harrington (1993) acrescenta o aumento da confiabilidade dos processos, a redução de estoques, o aumento da participação de mercado, a melhora no moral do pessoal e a redução da burocracia.

\section{Segundo a Association of Business} Process Management Professionals (ABPMP) (2013), a gestão de processos proporciona um novo olhar para a organização, passando das estruturas funcionais para uma visão do processo como um todo, compreendendo todos os setores e atividades envolvidas na sua execução, ou seja, não pode ser tratada como uma ferramenta, mas como uma nova cultura a ser desenvolvida no dia a dia da organização. Assim, o BPM pode ser considerado como um processo de transformação de processos na geração de valor para os clientes e para a sociedade (ABPMP, 2013).

Brocke e Rosemann (2013) definem Business Process Management (BPM) como um sistema abrangente de gestão e transformação de operações organizacionais sobre desempenho organizacional. Por meio de BPM, uma organização pode criar processos de alto desempenho, que funcionam com custos mais baixos, maior velocidade, melhor uso de ativos e maior flexibilidade.

Segundo Silva (2011), estudos têm mostrado que a gestão por processos é o fator de mudança do paradigma funcional para uma visão interfuncional, segundo a qual os conflitos oriundos da departamentalização passam a ser melhor geridos pelos processos. A esse respeito, Pimenta e Silva (2012) acreditam que, quando as organizações adotam sistemas de gestão por processos, inevitavelmente será requerida a formalização de determinados fatores de integração, tais como reuniões interfuncionais e planejamento, sendo assim, decisões gerenciais passam a ser internalizadas, compreendidas e decididas pela visão de processos. Porém, a organização que busca uma nova forma de gerenciar seus processos necessita conhecer o nível de integração e interdependência entre os processos, podendo resultar numa cultura participativa de mudança a partir dos desenhos dos processos. 
Zaiden (2013) enumera, como contribuições da gestão por BPM, a remoção de retrabalhos; a otimização de recursos; maior conformidade com normativas; o aumento da eficiência operacional; a uniformização de ferramentas e técnicas utilizadas; e maior clareza de responsabilidades. Portanto, a implantação do BPM, além de ser abrangente e complexa, poderá resultar em agilidade nas operações e resultados mais eficientes, visando garantir um modelo que não gere retrabalho perda de esforço e de eficiência. Assim, é imprescindível identificar as oportunidades de melhoria, que não se refere necessariamente à automatização da atividade.

\subsection{Gestão de Processo no Setor Público}

No cenário da Administração Pública, as mudanças são resultado das demandas da sociedade por maior transparência, rapidez e qualidade na prestação de serviços, o que tem contribuído para a busca da melhoria dos seus processos (Catelli \& Santos, 2004). Nessa perspectiva, o cidadão passa a ser visto como o cliente que recebe os serviços; já a organização, como um sistema integrado de provedores e clientes internos (Matias-Pereira, 2010).

Denhart (2012) considera que a gestão de processos vem sendo adotada como um novo modelo, conhecido como Administração Pública Gerencial, que busca implantar os princípios de produtividade, empreendedorismo e eficiência, sendo seu objetivo primordial reestruturar os processos para melhor atender aos cidadãos, promovendo mudanças relativas à desburocratização da máquina pública. Assim, as organizações públicas têm buscado adequar sua estrutura organizacional e seus processos internos, aprimorando seus modelos de gestão e otimizando seus sistemas de trabalho. Para que haja um diferencial qualitativo, Matias-Pereira (2010) entende que é preciso adotar ações inovadoras capazes de mobilizar todos os recursos disponíveis em busca de soluções eficientes e eficazes, dentro do processo das organizações públicas.

O Gespública, segundo o Manual do Brasil (2014), foi criado com o propósito de apoiar o desenvolvimento e a implantação de soluções que permitam um contínuo aperfeiçoamento dos sistemas de gestão das organizações públicas e de seus impactos junto aos cidadãos. Neste modelo, a gestão de processos é um mecanismo para identificar, representar, minimizar riscos e implementar processos de negócios dentro e entre organizações. A excelência da gestão pública, segundo Brasil (2014), será alcançada com a aplicação de protocolos e/ou processos que visem à otimização do trabalho, equidade da distribuição de tarefas e celeridade para atendimentos ao cliente/cidadão.

O programa Gespública ampliou seu escopo de atuação para três áreas: desburocratização, gestão do atendimento e modelo de excelência em gestão pública (De Carvalho Santana; De Souza-Silva, 2012). Um dos pontos estratégicos do programa foi a sua aplicação por toda administração pública, que foi impulsionada por sua adesão pelos mais 
variados órgãos públicos, sejam eles federais, estaduais ou municipais, como citado no Brasil (2014). Trata-se da Rede Nacional de Gestão Pública (RNGP), cuja difusão de experiências dos atores envolvidos demonstra a pretensão em atingir o que se entende por "estado da arte" da gestão contemporânea.

De acordo com o Modelo de Excelência em Gestão Pública, a gestão pública de excelência exige processos finalísticos e de apoio adequadamente estruturados, a partir da estratégia institucional, com base nos recursos disponíveis, nos requisitos dos públicos alvo e nas possibilidades e limitações jurídico-legais (Brasil, 2014). O monitoramento e o controle dos processos devem induzir mecanismos de tratamento de não conformidades e implantação de ações corretivas, melhoria dos processos e incorporação de inovações, de forma a assegurar o permanente alto desempenho institucional.

Por outro lado, Rosemann (2006) elencou o que ele chama de barreiras que a administração pública encontra na implantação de programas de gestão: a não utilização ou utilização de muitos métodos desordenados, falta de padronização, falta de alinhamento da iniciativa com a estratégia, resistência à mudança e falta de comprometimento e integração. Assim, o conhecimento destas variáveis e a consequente identificação de possíveis barreiras permitem ou fornecem subsídios às organizações com vistas à eliminação.

\section{Metodologia}

Nesta pesquisa, optou-se pela abordagem qualitativa, utilizando o estudo de caso como estratégia de pesquisa. O estudo de caso, segundo Yin (2005), é uma forma de fazer pesquisa social empírica ao investigar-se um fenômeno atual dentro de seu contexto de vida real, no qual as fronteiras entre o fenômeno e o contexto não são claramente definidas e na situação em que múltiplas fontes de evidência são utilizadas.

O estudo de caso é sustentado por um referencial teórico, que orienta as questões e proposições do estudo, reúne uma gama de informações obtidas por meio de diversas técnicas de levantamento de dados e "possibilita a penetração em uma realidade social, não conseguida plenamente por um levantamento amostral e avaliação exclusivamente quantitativa" (Martins, 2008, p. 11). Esta pesquisa configura-se em um estudo de caso, uma vez que busca compreender como um fenômeno se apresenta em uma única instituição: a DICP da Prefeitura de Belo Horizonte.

Vergara (2013) define o método de pesquisa qualitativo como um estudo não mensurável e de análise subjetiva. O principal objetivo da pesquisa qualitativa, segundo Zanelli (2002, p. 83), é "buscar entender o que as pessoas apreendem ao perceberem o que acontece em seus mundos". $\mathrm{Na}$ pesquisa qualitativa, de acordo com Creswell (2007), os investigadores mencionam as questões de pesquisa e procuram responder uma questão 
central. A teoria gera um padrão ou uma generalização que emerge indutivamente da coleta e análise de dados.

A coleta de dados foi realizada por meio de entrevistas individuais semiestruturadas e observação não participante direta. Segundo Flick (2004), a entrevista semiestruturada permite que os pontos de vistas dos sujeitos entrevistados sejam expressos em uma entrevista com um planejamento relativamente aberto. Ademais, neste modelo de entrevista o pesquisador elabora o questionário antes de ir a campo coletar os dados, porém, caso seja necessária a inserção de outras perguntas no momento da coleta dos dados, ele pode realizar tal ação sem problemas (Glesne, 2015).

A equipe era composta por 10 calculistas que atuavam na Diretoria há mais de 5 anos. Selecionou-se uma amostra por julgamento para operacionalização deste trabalho. Essa amostra é aquela em que o entrevistador de campo seleciona os sujeitos que irão compor o seu corpus de análise.

Somado a isso, para fazer parte do corpus de entrevistados, adotaram-se os critérios de tempo na diretoria, formação acadêmica e tempo de experiência com perícia. Nesse sentido, o critério para se escolher os entrevistados se deu por julgamento e com base nas experiências e responsabilidades que os mesmos possuem a respeito da rotina em estudo (MATTAR, 2001). Assim sendo, foram escolhidos 5 calculistas para compor o corpus da pesquisa.
Na Tabela 1, estão demonstrados os sujeitos entrevistados nesta pesquisa, a formação acadêmica e tempo de trabalho na DICP. 
Tabela 1 - Sujeitos da pesquisa

\begin{tabular}{|l|c|l|l|c|}
\hline Nome & Código & \multicolumn{1}{|c|}{$\begin{array}{c}\text { Nível de } \\
\text { Escolaridade }\end{array}$} & \multicolumn{1}{|c|}{ Formação Acadêmica } & Tempo na DICP \\
\hline Entrevistado 1 & E1 & $\begin{array}{l}\text { Superior Completo } \\
\text { e MBA }\end{array}$ & $\begin{array}{l}\text { Ciências Contábeis/MBA } \\
\text { Gestão Contábil e Tributária }\end{array}$ & 7 Anos \\
\hline Entrevistado 2 & E2 & $\begin{array}{l}\text { Superior Completo } \\
\text { e Especialização }\end{array}$ & $\begin{array}{l}\text { Ciências Contábeis/Perícia } \\
\text { Contábil }\end{array}$ & 10 Anos \\
\hline Entrevistado 3 & E3 & $\begin{array}{l}\text { Superior Completo } \\
\text { e Especialização }\end{array}$ & $\begin{array}{l}\text { Ciências Contábeis/Perícia } \\
\text { Contábil }\end{array}$ & 6 Anos \\
\hline Entrevistado 4 & E4 & $\begin{array}{l}\text { Superior Completo } \\
\text { e Especialização }\end{array}$ & $\begin{array}{l}\text { Ciências Contábeis/Perícia } \\
\text { Contábil }\end{array}$ & 5 Anos \\
\hline Entrevistado 5 & E5 & $\begin{array}{l}\text { Superior Completo } \\
\text { e Especialização }\end{array}$ & $\begin{array}{l}\text { Administração/Gestão de } \\
\text { Projetos } \\
\text { e Recursos Humanos }\end{array}$ \\
\hline
\end{tabular}

Fonte: Elaborada pelos autores.

As entrevistas individuais tiveram duração média de 30 minutos e permitiram conhecer as percepções e impressões que o grupo possui sobre o ambiente em que estão inseridos. A opção pela técnica de entrevista semiestruturada se deu em função de proporcionar ao entrevistador melhor entendimento e captação da perspectiva dos entrevistados, pois as entrevistas livres, ou seja, totalmente sem estrutura, durante as quais os participantes da pesquisa falam livremente, "resultam num acúmulo de informações difíceis de analisar que, muitas vezes, não oferecem visão clara da perspectiva do entrevistado" (Roesch, 1999, p. 159).

No decorrer do processo de análise do conteúdo das entrevistas, foi possível identificar um ponto de saturação teórica a partir da quinta entrevista realizada. Segundo Fontanella, Ricas e Turato (2008) e Thiry-Cherques, (2009), a saturação teórica ocorre quando os dados obtidos apresentam redundância ou repetição em relação à investigação do problema, isto é, não se identifica elemento novo que possa aumentar a quantidade de propriedade do objeto investigado. Diante disso, foi finalizada a coleta de dados por meio das entrevistas.

A análise de conteúdo foi utilizada para ajudar na reinterpretação das mensagens e numa melhor compreensão dos seus significados, podendo ser realizada sobre qualquer tipo de ato enunciativo (mensagem), por qualquer meio (Carlomagno \& Rocha, 2016). Os resultados da pesquisa foram apresentados por meio de categorias de análise, que representam o resultado de um esforço de sintetizar uma comunicação, elencando os aspectos mais relevantes (Olabuenaga \& Ispizúa, 1989).

Essa categorização estabelece critérios, que deverão ser seguidos, a fim de se classificar os elementos de uma mensagem. As categorias são: Processo de recebimento e Classificação do pedido; Processo de distribuição dos pedidos, Processo de entrega do produto final e Sugestões de melhoria no processo de trabalho.

$\mathrm{O}$ processo de recebimento e classificação do pedido representa a fase de entrada das demandas de conferência de cálculos dos processos judiciais, que são 
classificados quanto ao tema, prazo e valor. O quesito distribuição dos pedidos consiste na fase de partilha ou divisão dos processos judiciais entre os calculistas. Por fim, a entrega do produto final representa a saída e visa verificar se o resultado da conferência de cálculos, o parecer técnico, foi elaborado nos critérios da DICP e se foi cumprido o prazo de entrega. Nas sugestões de melhoria no processo de trabalho, serão identificadas as necessidades de ajustes e o que poderá ser aprimorado.

\section{Análise e discussão dos resultados}

Esta seção foi dividida em duas partes, com o intuito de obter melhor compreensão por parte do leitor. A primeira parte consiste em uma breve explanação sobre a unidade de análise deste trabalho, na qual são apresentados alguns aspectos e fatos importantes sobre a sua cronologia histórica. Em relação à segunda parte, apresentam-se os principais resultados obtidos a partir dos procedimentos empíricos aplicados nesta pesquisa. Tais resultados foram expostos a partir de quatro categorias temáticas, sendo elas: o Processo de recebimento e Classificação do pedido; o Processo de distribuição dos pedidos; o Processo de entrega do produto final e as Sugestões de melhoria no processo de trabalho.

\subsection{Caracterização do caso}

A origem da DICP está relacionada à criação de uma Comissão responsável pela revisão dos cálculos dos precatórios, constituída por meio da Portaria n. ${ }^{\circ} 3.574$ de 23 de janeiro de 1998, composta por auditores, procuradores e assistentes, vinculada ao Procurador Geral do Município. Foram convocados três auditores para analisarem e conferirem todas as ações judiciais na fase de execução de sentença e de pagamento de precatórios. Em 2005, em paralelo à Comissão de Precatórios, foi criada a Gerência de Cálculo, subordinada à Gerência Contenciosa, com atribuição de análise, conferência de cálculo e suporte aos Procuradores. Em janeiro de 2007 ocorreu a fusão da Comissão de Precatórios e da Gerência de Cálculo que originou a Gerência de Contas e Perícia Judicial (GEPJ), subordinada ao Procurador Geral do Município, com a atribuição descrita no art. 40 do Decreto n. ${ }^{\circ}$ 12.603/2007.

Em 2017, com a reforma administrativa instituída pela Lei 11.065, a Gerência de Contas e Perícia Judicial foi transformada em Diretoria de Cálculos e Perícias e teve suas atribuições dispostas no art. 25 do Decreto n. ${ }^{\circ} 16.683 / 17$, quais sejam: planejar, coordenar e avaliar a atividade de elaboração de memória de cálculo, atendendo todas as Gerências da ProcuradoriaGeral do Município que necessitem de serviços dessa natureza, inclusive precatórios judiciais; planejar, orientar e supervisionar a atividade de conferência de cálculos apresentados pela parte contrária para subsidiar a atuação do Município; emitir parecer contábil por solicitação do Gabinete da PGM ou dos subprocuradores; prestar assistência técnica nas perícias de interesse do Município; promover os atos administrativos e periciais necessários à 
conferência de cálculos e à tramitação administrativa dos processos de compensação tributária, pagamento de Requisições de Pequeno Valor (RPV), pagamento de precatórios e ordens judiciais de bloqueio de valores em contas do Município; prestar informações sobre o pagamento de RPV e precatórios.

Atualmente, a DICP é responsável pela análise de ações judiciais, tanto físicas quanto eletrônicas. A forma eletrônica foi introduzida em 2015, com o objetivo de conferir maior celeridade e eficiência do judiciário, com o nome de Processo Judicial Eletrônico (PJE). No ano de 2017, foram analisadas 4.085 ações judiciais. Em 2018, foram 5.137 apontando um crescimento de $25,75 \%$ do número de ações judiciais analisadas pela DICP de 2017 para 2018. Esse aumento decorreu em grande parte pela introdução do PJE, pois a sua tramitação é mais rápida, e, também, devido ao crescimento da judicialização dos conflitos.

\subsection{Análise dos resultados}

No tocante ao processo de recebimento de demanda, o objetivo é analisar a entrada dos pedidos de conferência de cálculos na DICP e sua organização e classificação quanto ao tema, ao prazo e valor. Os pedidos de análise de ações judiciais eletrônicas são recebidos no e-mail da diretoria. Não há um sistema de informação que faça o controle eletrônico desses pedidos. Eles são encaminhados pelos procuradores e pelos assistentes de cada subnúcleo.
Já os pedidos dos processos físicos são recebidos na DICP, juntamente com os mesmos. A demanda originada dos processos físicos representa cerca de $15 \%$ do total. O restante são os pedidos oriundos do PJE que são analisados e classificados quanto ao prazo, tema e valor. Na sequência, são organizados e alocados numa bandeja na prateleira onde ficam aguardando para serem analisados e conferidos pelos calculistas.

Tal dinâmica corrobora Crawford (2002), em que um Escritório de Projetos pode ser constituído por poucas pessoas que se debruçam em tarefas de preparo e elaboração de cronogramas, ou podem ser também estruturas supercomplexas composta por várias pessoas que realizam planejamento, controle de informações e gestão de projetos.

A utilização de Escritório de Projetos colabora para a padronização de operações por meio de análise e mapeamento de processos; amplia a capacidade de planejamento por meio de uma alocação eficiente de recursos; propicia acesso à informação de maior qualidade; apresenta menor necessidade de reestruturação organizacional; e, sobretudo, prioriza uma visão realista do escritório, conforme PMI (2013).

Os entrevistados E3 e E4 relataram a ocorrência de retrabalho em suas atividades. É possível haver duplicidade de pedidos, uma vez que não há um controle a nível de Sistemas de Informação Gerenciais (SIG). Segundo Zaiden (2013), a gestão por BPM pode contribuir para a remoção de retrabalhos. 
Outro benefício com a gestão por BPM, segundo este mesmo autor, é a conformidade com normativas.

Os entrevistados E2 e E5 afirmam que a falta de padronização dos pedidos feitos provoca desperdício de tempo e dificuldades de localização. Geralmente, como os pedidos são feitos por pessoas diferentes e cada um os registra de uma forma, em algumas situações, as informações são incompletas, falta critério na definição de prazo de entrega do Parecer, e ainda é comum o envio de pedido sem motivos para análise de cálculos.

A falta de padronização gera retrabalho e desgaste entre as partes interessadas. O entrevistado E5 relata que, quando faltam dados no pedido e não é possível a identificação ou há dúvidas sobre o objeto do pedido, é necessário requerer que o solicitante complete as informações ou esclareça as dúvidas. Quando o arquivo eletrônico está incompleto ou desatualizado, o entrevistado E5 afirma que é necessário baixar o processo no site do Tribunal.

Quanto aos prazos de entrega do Parecer Técnico, estes são analisados novamente na Diretoria e, quando há equívocos, os mesmos são retificados, conforme acordado na época de implantação do PJE. O prazo de entrega dos Pareceres está relacionado ao prazo deferido na ação judicial. Nesse sentido, Matias-Pereira (2010) entende que é preciso adotar ações inovadoras capazes de mobilizar todos os recursos disponíveis em busca de soluções eficientes e eficazes, dentro do processo das organizações públicas.

Há relatos de desperdício de tempo, falta de padronização de tarefas e falta de mobilização dos recursos para atender o objetivo maior da Diretoria que é a conferência de cálculos.

No tocante ao Processo de Distribuição dos Pedidos, o objetivo foi analisar como é realizada a distribuição dos pedidos entre os calculistas. A seguir, apresentaremos uma breve descrição do mapeamento do processo de distribuição dos pedidos de conferência de cálculos na DICP.

Atualmente, a distribuição somente é feita pela Diretoria quando chegam pedidos com prazos urgentes. A separação por assuntos faz com que certos calculistas selecionem os processos de temas do seu domínio. Todavia, quando alguma área fica sobrecarregada pelo volume de pedidos, a Diretoria aloca os demais calculistas para auxiliarem, a fim de cumprir o prazo de entrega. Todos os calculistas relatam a sobrecarga de trabalho, que pode comprometer a qualidade dos pareceres, pois os profissionais precisam analisar de forma mais sucinta as ações e darem conta de responderem aos pedidos no prazo solicitado.

Para o Processo de Entrega do Produto Final, nessa categoria, o objetivo foi verificar se o parecer técnico é entregue com qualidade no prazo solicitado. A seguir, será apresentada uma breve descrição do mapeamento do processo de entrega do produto final na DICP. 
Todos os entrevistados relataram que na análise e conferência das ações judiciais utilizam a mesma metodologia, que é a leitura da mesma, registro dos dados relevantes e consultas a sistemas e publicações. E, quando necessário, são requisitados documentos para esclarecimentos ou comprovação de fatos.

$\mathrm{O}$ entrevistado E3 menciona que a complexidade de uma ação judicial poderá impactar o cumprimento do prazo do parecer, além de sobrecarregar os demais calculistas. Ainda para o entrevistado E3, numa ação judicial complexa, o calculista necessita de vários dias para analisar, conferir cálculos e elaborar o parecer.

Outra questão evidenciada a partir das falas dos entrevistados E2 e E3 refere-se à dificuldade na busca de informações e documentos em outros órgãos municipais que são imprescindíveis no processo de conferência de cálculos e elaboração do parecer técnico para apurar possíveis acertos já realizados ou delimitar o período de acerto financeiro. Além do mais, o entrevistado E3 pontua que são necessários no mínimo sete dias para obter um processo administrativo que já esteja arquivado.

Sobre os dados registrados no prontuário do servidor, como quinquênio e férias-prêmio, a gerência responsável pela contagem de tempo tem que requisitá-lo em outro setor, para responder nossa solicitação. No caso dessa gerência, dois dos entrevistados relataram atrasos na entrega de tais dados, ou os mesmos sequer foram enviados.
Outra questão levantada pelo E2 é com relação à progressão, pois os registros no sistema de recursos humanos são carentes de informações, e, muitas vezes, é necessário requisitar cópias de requerimentos administrativos e históricos de progressão, que nem sempre são fornecidas ou disponibilizadas no prazo hábil.

Ainda relacionado ao tema dificuldade, numa situação relatada pelo entrevistado $E 4$, ele afirma que teve que realizar oito ligações para diversas gerências da Secretaria de Saúde para obter uma simples informação quanto ao pagamento de abono de estímulo fixação. A falta ou o atraso das informações poderá implicar pareceres incompletos, perda de prazo, possíveis pagamentos em duplicidade, podendo ocorrer danos ao erário, conforme evidenciado pelos entrevistados E2 e E3.

Por outro lado, quando ocorre alguma indisponibilidade dos sistemas eletrônicos, isso poderá comprometer a conferência de cálculos e os prazos de entrega do parecer, conforme pontua o entrevistado E3. Como a maior parte do trabalho da DICP depende da rede de internet, qualquer queda, falha e/ou instabilidade de qualquer sistema afetam diretamente toda a produção.

\section{O mapeamento dos processos na DICP} é uma das melhorias apontadas. Os entrevistados foram unânimes quanto à centralização dos pedidos de conferência de cálculos, isto é, os mesmos deveriam ser enviados para o e-mail da diretoria. Além 
disso, os entrevistados E2, E3, E4 e E5 indicaram a necessidade de padronização dos pedidos.

Outra padronização sugerida foi indicada pelos entrevistados E4 e E5. Trata-se de instrumentos de monitoramento dos pedidos de conferência de cálculos, para facilitar a sua localização na diretoria, pois, quando o procurador ou o núcleo acusam pendências, perde-se muito tempo com pesquisa.

Os entrevistados E2 e E5 indicaram que as ações judiciais deveriam ser mapeadas e agrupadas em níveis, de baixa, média e alta complexidade. Além disso, o entrevistado E5, além de sugerir o agrupamento das ações judiciais, indica que a equipe de calculistas também deveria ser organizada em três grupos, utilizando os parâmetros de classificação das ações judiciais, para aumentar a produção. E, para o E3, o calculista deveria realizar a conferência de assuntos de seu domínio.

Já o entrevistado E2 pontua que todos os calculistas da equipe deveriam ter condições de realizar a conferência de qualquer processo, ou seja, deveriam conhecer todos os assuntos, ser multidisciplinar. Ele ainda sugere que os cálculos de valor irrelevante não deveriam ser conferidos.

Para o entrevistado E5, o processo de trabalho da DICP poderia ser agilizado com a elaboração de um checklist de conferência de processos e outro de elaboração de parecer técnico, pois, se houvesse "uma receita de bolo", seria mais fácil e ágil entregar um produto final padronizado.

As organizações estão buscando inovações. Para Marzall et al. (2016), a inovação tem se demonstrado uma estratégia organizacional que permite que uma organização possa mensurar seus resultados e implementar medidas que impactam o desempenho da mesma.

Assim, o entrevistado E2 ainda indicou a necessidade de que os procuradores atualizem a diretoria sobre a mudança de posicionamento do judiciário, quando determinado posicionamento do Município passa a não ser acatado a fim de evitar multas. Ademais, evidenciou-se a necessidade de realização de reuniões periódicas com a equipe para planejamento, compartilhamento de decisões e busca de soluções, visando unificar as informações e integrá-las, conforme pontuado pelos entrevistados E2, E3 e E4.

Sobre a dificuldade de se obter informações e documentos imprescindíveis no processo de conferência de cálculos e elaboração do parecer técnico em outros órgãos municipais, foi indicado pelos entrevistados E2, E3, E4 e E5 que seria necessário melhorar o relacionamento e o fluxo das solicitações com os setores, para se ter acesso às informações e criar condições para que sejam disponibilizadas em tempo hábil. 


\section{Considerações finais}

A presente pesquisa teve como objetivo geral analisar como o processo de trabalho dos calculistas é desenvolvido na Diretoria de Cálculos e Perícias da Procuradoria Geral do Município de Belo Horizonte, para identificar e apresentar protocolos no fluxo de trabalho, visando à otimização dos recursos e qualidade na entrega do produto final, tendo em vista o crescimento da demanda, decorrente do aumento do número de ações judiciais contra o Município e da celeridade imposta pela informatização dos tribunais, através da implantação da ação judicial eletrônica, denominada PJE.

Os objetivos específicos propostos foram mapear e analisar as principais dificuldades encontradas no processo e identificar oportunidades de melhoria.

A proposta era investigar como o processo de trabalho na DICP poderia ser estruturado com vistas a obter melhorias em seu conjunto de atividades. Para otimizar os recursos e entregar o parecer técnico no prazo solicitado, seria necessário: o redesenho dos fluxos, a padronização dos processos, a adoção do checklist de conferência e de elaboração do parecer, a implantação de um sistema de monitoramento, a realização de reuniões com a equipe para planejamento e buscar soluções, visando a uma maior integração e participação.

Os resultados apontaram que, para se ter uma distribuição equânime dos pedidos de conferência entre os calculistas, as ações judiciais teriam que ser mapeadas e agrupadas em níveis de baixa, média e alta complexidade. Apesar de ser necessária uma equipe generalista, os calculistas deveriam ser divididos em três grupos, para atender os parâmetros de classificação das ações judiciais, aspirando à otimização do tempo e dos recursos, ao aumento da produtividade e à qualidade do produto final.

Indicaram, também, que o número de calculistas é inferior à real necessidade da diretoria, tendo em vista a constatação da sobrecarga ocasionada pelo volume de pedidos e agravada por aqueles de caráter "urgentes", que impactam tanto a qualidade quanto o cumprimento dos prazos de entrega. Em determinadas situações, faz-se necessária uma análise mais objetiva e direta dos processos, bem como o deslocamento de calculistas de outro setor a fim de atender à demanda.

Quanto à relação com os órgãos externos à PGM, apurou-se a necessidade de aprimorar a comunicação e integrar as partes envolvidas na execução das ações judiciais, tendo em vista que a Diretoria desenvolve a atividade-meio, e os dados e informações de outros setores do Município são imprescindíveis no processo de conferência de cálculos e elaboração do parecer técnico.

A relevância desta pesquisa é, além da sua aplicabilidade quanto ao mapeamento e à padronização dos processos na esfera pública, buscar alternativas para aperfeiçoamento de processos juntamente com os atores integrantes da equipe para apresentar sua percepção do trabalho e indicar melhorias, ao mesmo tempo 
que proporciona ao gestor uma visão do conjunto de soluções mais adequadas para sistematizar os recursos, reduzir prazos, entregar produtos com qualidade e eficiência.

Os resultados apresentam possíveis desdobramentos, bem como sugestões para estudos futuros voltados para uma análise mais aprofundada da intercomunicação com os demais setores internos da PGM que interagem com a DICP, destacando a importância de se conhecer o funcionamento da procuradoria, proporcionando uma visão panorâmica de como deve ser o envolvimento de cada pessoa e o quanto ela representa no processo como um todo.

A necessidade de mapeamento de processos deve ser realizada levando em consideração o conhecimento de cada servidor, com a elaboração de modelos de processos, que, em seguida, são transformados em manuais padrões, que venham a ser implementados por gestores preocupados com essa visão. Ademais, é crucial tenham condições de promover mudanças significativas, pois a gestão de processos visa a melhorias e exige um trabalho cíclico de análise das atividades executadas e o comprometimento das equipes.

As limitações do estudo dizem respeito a uma cultura burocrática existente no serviço público, que impõe rotinas diferenciadas no dia a dia da organização. E ao considerar que a implementação é resultante de um contexto organizacional, percebe-se a importância de se ofertar uma maior visão de todo o processo, mapeando, de forma clara, todas as áreas envolvidas, com o objetivo de propiciar aos gestores um diagnóstico real e transparente e, desta forma, sensibilizá-los para promover as mudanças necessárias.

\section{Referências}

Association of Business Process Management Professionals. (2013). Guia para o Gerenciamento de Processos de Negócios. Corpo Comum de Conhecimento. ( $1^{\mathrm{a}} \mathrm{ed}$.). São Paulo: BPM Brazil.

Adair, C. B. \& Murray, B. A. (1996). Revolução total dos processos. São Paulo: Nobel.

AXELOS. (2016). Introduction to P3M3. Recuperado em 11.10.2020 de: https://www.axelos.com/getmedia/9552436eee38-443d-afd9-37d445ce5157/Intro-toP3M3.aspx

BELO HORIZONTE. (2019). Lei n. ${ }^{\circ} 11.065$. Recuperado em 18.10.2020 de: http://www.cmbh.mg.gov.br

BELO HORIZONTE. (2017). Organograma da Procuradoria Geral do Município. Prefeitura Municipal de Belo Horizonte As empresas são grandes coleções de processos. Recuperado em 21.10.2020 de: https://prefeitura.pbh.gov.br/sites/default/file s/noticia/ORG_PGM.pdf

BELO HORIZONTE. (2017). Decreto n. ${ }^{\circ}$ 16.683. Recuperado em 21.10.2020 de: http://www.cmbh.mg.gov.br

BELO HORIZONTE. (2007). Decreto Municipal n. ${ }^{\circ}$ 12.603. Recuperado em 20.10.2020 de: http://www.cmbh.mg.gov.br

BELO HORIZONTE. (1998). Portaria $n^{\circ}$ 3.574. Recuperado em 10.09.2020 de: http://www.cmbh.mg.gov.br

BRASIL. (2014). Lei 13.105. Código de Processo Civil. Recuperado em 10.09.2020, 
de:

http://www.planalto.gov.br/ccivil_03/_Ato20 15-2018/2015/Lei/L13105.htm

Ministério do Planejamento, Orçamento e Gestão. (2014) Gespública. Guia de Gestão de Processos.

Brocke, J. V. \& Rosemann M. (2013). Manual de BPM: Gestão de Processos de Negócio. (1a ed.). São Paulo: Bookman.

Carlomagno, M. \& Rocha, L. (2016). Como criar e classificar categorias para fazer análise de conteúdo: uma questão metodológica. Revista Eletrônica de Ciência Política, 7(1), 173-188.

Catelli, A. \& Santos, E. (2004). Mensurando a criação de valor na gestão pública. Revista de Administração Pública, 38(3), 423-450.

Creswell, J. W. (2007). Projeto de pesquisa: métodos qualitativo, quantitativo e misto. Tradução Luciana de Oliveira da Rocha. (2a ed.). São Paulo: Artmed.

Crawford, J. K. (2002). The strategic project office: A guide to improving organizational performance. Marcel Dekker Inc.

Cruz, C. F; Ferreira, A. C. S.; Silva, L. M. \& Macedo, M., A. S. (2012). Transparência da gestão pública municipal: um estudo a partir dos portais eletrônicos dos maiores municípios brasileiros. Revista de Administração Pública, 46(1), 153-176.

Davenport, T. H. (1994). Reengenharia de processos. ( $2^{\mathrm{a}} \mathrm{ed}$.) Rio de Janeiro: Campus.

Denhart, R. B. (2012). Teorias da administração pública. Tradução Francisco G. Heidemann. São Paulo: Cengage Learning.

De Sordi, J. O. (2005). Gestão por processos: Uma abordagem da moderna administração. ( $2^{\mathrm{a}}$ ed.). São Paulo: Saraiva.

Dixon, J. (2012). Hype Cycle for Business Process Management. Recuperado em 10.10.2020 de: https://www.gartner.com/doc/2096519?ref= mrktg-srch.

Flick, U. (2004). Uma introdução à pesquisa qualitativa. ( $2^{\mathrm{a}}$ ed.). São Paulo: Bookman.

Gonçalves, J. E. L. (2000). As empresas são grandes coleções de processos. Revista de Administração de Empresas, 40(1), 6-9.

Glesne, C. (2015). Becoming qualitative researchers: An introduction. 5th edition. London: Pearson.

Harrington, H. J. (1993). Aperfeiçoando processos empresariais: Estratégia revolucionária para o aperfeiçoamento da qualidade, da produtividade e da competitividade. Makron Books.

Huntress, J. (2006). The Current State of BPM Technology: A taxonomy and strategy. BPM Institute.

Longaray, A. A.; Munhoz, P. R.; Silveira, L. S.; Lunardi, G. L. \& Duarte, S. (2017). Proposta de Mapeamento de Processos Usando a BPMN: Estudo de Caso em uma Indústria da Construção Naval Brasileira. Revista Eletrônica de Estratégia \& Negócios, 10 (Ed. Especial 2), 247-275.

Martins, G. A. (2008). Estudo de caso: uma reflexão sobre a aplicabilidade em pesquisa no Brasil. Revista de Contabilidade e Organizações, 2(2), 9-18.

Marzall, L.; dos Santos, L. \& Godoy, L. (2016). Inovação no projeto de produto como fator para redução de custos logísticos e de produção. Revista Produção Online, 16(1), 342-365.

Mattar, F. N. (2001). Pesquisa de marketing. ( $3^{\mathrm{a}}$ ed.). São Paulo: Atlas.

Matias-Pereira, J. (2010). A governança corporativa aplicada no setor público brasileiro. Administração Pública E Gestão Social, 2(1), 109-134. Recuperado em 05.10. 2020 de: https://periodicos.ufv.br/apgs/article/view/40 15. 
Mendonça, R. R. S. de. (2014). Processos Administrativos. Departamento de Ciências da Administração/UFSC. ( $3^{a}$ ed.) Brasília: Capes.

Kelm, M.; Baggio, D.; Kelm, M.; Griebeler, M. \& Sausen, J. (2015). A inovação como estratégia competitiva das organizações: um ensaio teórico. Revista de Administração IMED, 4(3), 274-285.

Palvarini, B. C. (2009) O que é Gespública. Brasília. Recuperado em 11.10.2020 de: https://pt.slideshare.net/UltimaRatio1/o-quea-gespublica.

Paim, R.; Caulliraux, H. M. \& Cardoso, R. (2008). Process management tasks: a conceptual and practical view. Business Process Managament Journal, 14 (5) 694 723.

Pimenta, M. L. \& Silva, A. L. (2012). Desafios da integração interfuncional: O papel da formalidade e da informalidade. In: XXXVI Encontro Nacional da Anpad. Rio de Janeiro. Anais. Rio de Janeiro: Anpad, 25-36.

Pradella, S. (2013). Gestão de processos: Uma metodologia redesenhada para a busca de maior eficiência e eficácia organizacional. Revista Gestão \& Tecnologia. [S.1.], 13(2), 94-121.

PMI. (2013). Project Management Professional (PMP) Handbook. Newton Square: Project Management Institute.

Roesch, S. M. A. (1999). Projetos de estágio e de pesquisa em administração. ( $3^{\mathrm{a}} \mathrm{ed}$.) São Paulo: Atlas.

Rosemann, M. (2006). Potential pitfalls of process modeling: Part A. In: Business
Process Management Journal, 12(2), 249 254.

Santana, R. S. C. \& Silva, J. C. S. (2012). A contribuição do modelo de excelência em gestão pública no processo de aprendizagem organizacional: o caso da Empresa Baiana de Águas e Saneamento S.A. Gestão e Sociedade, 6(13), 47-68.

Sá, A. L. (2011). Perícia Contábil. (2 ${ }^{\mathrm{a}}$ ed.) São Paulo: Atlas.

Silva, A. L. (2011). Dinâmica de integração interfuncional entre marketing, logística e produção: novos caminhos para a gestão de operações. São Paulo: FAPESP.

Thiry-Cherques, H. R. (2009). Saturação em pesquisa qualitativa: estimativa empírica de dimensionamento. Revista PMKT, 3(2), 20 27.

Vergara, S. C. (2013). Projetos e relatórios de pesquisa em administração. (15 ${ }^{\mathrm{a}}$ ed.) São Paulo: Atlas.

Warrington, E. (1977). Tree Vies of the New Public Administration. Public Administration and Development.

Yin, R. K. (2005). Estudo de caso: Planejamento e métodos. (5a ed.). São Paulo: Bookman.

Zaiden, J. A. S. (2013). Escritório de processos: Otimizando a gestão pública do Estado de Goiás. In: Congresso Consad de Gestão Pública. Brasília.

Zanelli, J. C. (2002). Pesquisa qualitativa em estudos de gestão de pessoas. Estudos da Psicologia, 7, 79-88. 